\title{
Periprocedural soluble P- and E-selectin levels fail as predictors of clinical restenosis in patients treated with elective coronary stenting
}

\author{
MAREK KOZINSKI ${ }^{1}$, JACEK KUBICA ${ }^{1}$, ADAM SUKIENNIK ${ }^{1}$, MAGDALENA ZBIKOWSKA-GOTZ ${ }^{2}$, \\ ANNA KRZEWINA-KOWALSKA ${ }^{1}$, MAREK RADOMSKI ${ }^{1}$, MARCIN RYCHTER $^{1}$, TOMASZ BIALOSZYNSKI ${ }^{1}$, \\ MIROSLAW JABLONSKI ${ }^{1}$, KRZYSZTOF DEMIDOWICZ ${ }^{1}$, GRZEGORZ GRZESK ${ }^{1}$, MARIA BOGDAN ${ }^{1}$, \\ MACIEJ CHOJNICKI ${ }^{1}$, SOFIA GRABCZEWSKA ${ }^{1}$ and ANDRZEJ DZIEDZICZKO ${ }^{2}$ \\ ${ }^{1}$ Department of Cardiology and Internal Diseases, Collegium Medicum, Nicolaus Copernicus University, \\ 9 Sklodowskiej-Curie Street, 85-094 Bydgoszcz; ${ }^{2}$ Department of Allergology and Internal Diseases, \\ Collegium Medicum, Nicolaus Copernicus University, 75 Ujejskiego Street, 85-168 Bydgoszcz, Poland
}

Received August 16, 2006; Accepted September 29, 2006

\begin{abstract}
An increasing amount of basic scientific data indicates that adhesion molecules may be involved in the pathogenesis of vessel re-narrowing in patients undergoing coronary angioplasty. Furthermore, inflammation is suggested to be a pivotal mechanism linking atherosclerosis and restenosis. The aim of this study was to assess if periprocedural evaluation of soluble P-selectin (sP-selectin) and E-selectin (sE-selectin) possesses any additive value in the restenosis prediction to $\mathrm{C}$-reactive protein (CRP) measurement. One hundred and nine stable angina patients were consecutively enrolled into the prospective cohort study. All participants were treated with single vessel coronary bare metal stenting. sP-selectin, sE-selectin and CRP were measured in peripheral venous blood samples collected before and $6,24 \mathrm{~h}$ and 1 month after the procedure. Clinical follow-up visits were held 7 days* ${ }^{*} 1^{*}, 3,6^{*}$, and 12 months (*with an exercise test) after stenting. Any symptoms of restenosis were verified angiographically. Clinical restenosis occurred in 18 subjects. Concentrations of sP-selectin and sE-selectin did not differ between patients with and without clinical restenosis at any measuring point. In the latter group a decrease in sP-selectin and sE-selectin levels was observed $6 \mathrm{~h}$ after stenting. These findings when considered in all of the investigated subjects had no impact on the subsequent incidence of restenosis. An
\end{abstract}

Correspondence to: Dr Marek Kozinski, Department of Cardiology and Internal Diseases, Collegium Medicum, Nicolaus Copernicus University, 9 Sklodowskiej-Curie Street, 85-094 Bydgoszcz, Poland

E-mail: marekkozinski@wp.pl

Key words: soluble P-selectin, soluble E-selectin, C-reactive protein, elective coronary stenting, clinical restenosis, risk stratification inflammatory response assessed as an increase in CRP level with the peak values at $24 \mathrm{~h}$ was noted in the whole population. However, it was significantly more pronounced in the restenosis group. Application of the Cox's proportional hazard model revealed a high CRP level $24 \mathrm{~h}$ after stenting and the history of coronary angioplasty concerning a nontarget lesion to be the only independent predictors of clinical restenosis. To conclude, the periprocedural evaluation of sP-selectin and $\mathrm{sE}$-selectin in peripheral venous blood in patients undergoing elective coronary stenting provides no prognostic information in terms of clinical restenosis prediction, and the magnitude of the systemic inflammatory response triggered by coronary angioplasty assessed as an increase in CRP level and the history of coronary angioplasty concerning nontarget stenosis remain independent predictors of lesion re-narrowing.

\section{Introduction}

Percutaneous transluminal coronary angioplasty (PTCA) has become the most widely implemented method of heart revascularization. However, it is estimated that each year approximately 250,000 patients worldwide experience restenosis after initially successful PTCA (1). Vessel renarrowing manifesting itself as a recurrence of angina leads to the necessity of target vessel reintervention and substantially impairs the quality of life of the patient. Although drug-eluting stents (DES) are suggested as a very effective approach to the prevention and treatment of restenosis, their application alters the vessel healing process that may result in late acute stent thrombosis and an increased rate of subsequent myocardial infarctions $(2,3)$. Therefore, until the long-term outcome of comparisons between DES and modern bare metal stents are obtained, caution in the choice of a particular device for each patient is advised. Furthermore, according to a recent study considering the cost-effectiveness of DES, their use in a clinical setting should be restricted to subjects with a high risk of restenosis (4). Besides clinical, angiographic and 
procedure-related risk factors, inflammatory marker evaluation emerges as a promising adjunctive strategy for the stratification process of patients undergoing coronary stenting.

The adhesion of activated leukocytes to the injured arterial wall and their subsequent extravasation are thought to be critical steps in the development of restenosis. Selectins, a family of cell adhesion molecules, mediate the initial attachment of platelets and the rolling interaction of leukocytes with the luminal endothelium (5). E-selectin is exclusively expressed in endothelium, whereas P-selectin is present on platelets and in secretory bodies (Weibel-Palade) in endothelial cells. Enzymatic cleavage of the extracellular portion of selectins or alternative splicing of mRNA encoding for these molecules can yield circulating forms which can be measured from sampled serum and are referred to as soluble cellular adhesion molecules $(6,7)$. Population-based trials provide evidence for the association between high levels of soluble selectins and the increased risk of major cardiovascular events in patients with existing peripheral or coronary atherosclerosis (8-10) and in apparently healthy women (11). In numerous experimental studies, the inhibition of P- and E-selectin expression or their inactivation were proven to substantially reduce the neointimal formation and the occurrence of restenosis (12-17). In previously published studies, we and other authors have demonstrated that the magnitude of C-reactive protein increase after bare metal stenting correlates with the risk of restenosis $(18,19)$ and the periprocedural multi-marker evaluation in this setting may enhance the prediction of vessel re-narrowing after PTCA (20).

The aim of this study was to assess if the periprocedural evaluation of soluble P-selectin (sP-selectin) and E-selectin (sE-selectin) in peripheral venous blood possesses any additive value in the prediction of restenosis to CRP measurement.

\section{Materials and methods}

Study design and patients. This study was designed as a single-center prospective observational cohort trial with a 1-year follow-up. One hundred and nine stable angina patients with coronary artery disease diagnosed by coronary angiography and referred to our department for PTCA were prospectively enrolled in the study. All subjects were interviewed to obtain the most detailed medical history (with a special emphasis on comorbidity) and underwent a physical examination, echocardiography and blood sampling for creatinine, total cholesterol, HDL-cholesterol, LDLcholesterol and triglycerides. The characteristics of the group are presented in Table I. Clinical exclusion criteria included any concomitant inflammatory process, neoplastic disease, use of steroids, immunosuppressive and non-steroidal antiinflammatory treatment (excluding low doses of aspirin) for 3 months prior to the trial; myocardial infarction or unstable angina for 6 months before the trial; preprocedural myocardial necrosis (positive cardiac troponin I test); heart failure (clinical symptoms of heart failure in at least class II according to NYHA and/or left ventricular ejection fraction $<30 \%$ ); and renal failure (serum creatinine levels $>1.5 \mathrm{mg} / \mathrm{dl}$ ).

Clinical follow-up visits were held 7 days ${ }^{*}, 1^{*}, 3,6^{*}$, and 12 months (*with a treadmill stress test according to the Bruce protocol) after the procedure. Any symptoms of restenosis (recurrent chest pain or newly-diagnosed ischemic alterations in a treadmill stress test, i.e. the significant deterioration of exercise capacity in patients with consistently positive treadmill stress test results) were verified angiographically. The primary end point for the study was angiographic evidence of clinical restenosis after 1 year.

All participants provided informed written consent, and the study protocol was approved by the local ethics committee.

Coronary angiography and stenting. Coronary angiography via the femoral approach using a standard technique was performed. Non-ionic contrast agents were administered in all patients. Angiographic exclusion criteria comprised restenosis as a reason for PTCA, angioplasty of venous or arterial graft, PTCA of a bifurcation lesion, diameter of referential segment $<2.5 \mathrm{~mm}$, angioplasty of left main stenosis, and recanalisation of chronic total occlusion. All participants were treated with single vessel bare metal stenting. Detailed characteristics of the procedures are displayed in Table II. Residual stenosis not exceeding $20 \%$ of the referential diameter was considered as a procedural success. Prior to the intervention, unfractionated heparin $(100 \mathrm{IU} / \mathrm{kg})$ was injected intravenously. Over a minimum of two days before the intervention, all patients were pre-treated with ticlopidine (250 mg/twice daily). Additionally, ticlopidine was administered for 1 month and aspirin indefinitely after PTCA. In subjects referred for control coronary angiography, the procedure was performed with at least 5 projections for the left coronary artery and 3 projections for the right coronary artery after an intracoronary injection of nitroglycerine $(0.3 \mathrm{mg})$. Stenoses were visually assessed by an experienced operator at the projection where they were the narrowest. For stenoses ranging from $40-70 \%$ an additional quantitative measurement (DFP-60A, Toshiba Co, Japan) was applied. Restenosis was defined as a recurrent luminal narrowing $>50 \%$ when compared with a referential segment at the site of the earlier intervention.

Measurement of biomarkers. Peripheral venous blood samples were collected immediately before angiography and $6 \mathrm{~h}, 24 \mathrm{~h}$ and 1 month after the procedure. When centrifuged, the sera were stored at $-80^{\circ} \mathrm{C}$ until analysed.

Serum cardiac necrosis markers were determined by a microparticle enzyme immunoassay kit (AxSYM Troponin-I, Abbott Laboratories, Abbot Park, IL, USA).

All inflammatory markers were measured in duplicate, and the results were averaged. sP-selectin and sE-selectin were evaluated by enzyme-linked immunosorbent assay (ELISA) kits (Bender MedSystems Diagnostics GmbH, Vienna, Austria). High-sensitivity CRP was measured by a nephelometric method using a commercially available N Latex high-sensitivity CRP test on Behring Nephelometer II (Dade Behring, Marburg, Germany). The sensitivity limits for sP-selectin, sE-selectin and CRP were $1.3 \mu \mathrm{g} / 1,0.33 \mu \mathrm{g} / \mathrm{l}$ and $0.175 \mathrm{mg} / 1$, respectively. The intra-assay coefficients of variations $(\mathrm{CV})$ were $6.5 \%$ for sP-selectin, $6.9 \%$ for sE-selectin and $3.3 \%$ for CRP, while inter-assay CVs were $5.5 \%$ for $\mathrm{sP}$-selectin, $7.5 \%$ for $\mathrm{sE}$-selectin and $3.2 \%$ for CRP, respectively. 
Table I. Clinical characteristics of patients on the day of PTCA.

\begin{tabular}{|c|c|c|c|c|}
\hline Parameter & $\begin{array}{l}\text { The entire cohort } \\
\qquad(n=109)\end{array}$ & $\begin{array}{l}\text { Restenosis }(+) \\
\quad(n=18)\end{array}$ & $\begin{array}{l}\text { Restenosis }(-) \\
\quad(n=91)\end{array}$ & $\mathrm{p}$ \\
\hline Age (years) & $\begin{array}{c}57.5 \\
(51.0-64.0)\end{array}$ & $\begin{array}{c}61.5 \\
(53.0-66.0)\end{array}$ & $\begin{array}{c}57.0 \\
(51.0-64.0)\end{array}$ & ns \\
\hline $\operatorname{Sex}(\mathrm{M} / \mathrm{F})$ & $84 / 25(77 \% / 23 \%)$ & $13 / 5(72 \% / 28 \%)$ & $71 / 20(78 \% / 22 \%)$ & ns \\
\hline $\mathrm{BMI}\left(\mathrm{kg} / \mathrm{m}^{2}\right)$ & $\begin{array}{c}27.5 \\
(25.5-29.7)\end{array}$ & $\begin{array}{c}26.8 \\
(26.0-29.7)\end{array}$ & $\begin{array}{c}27.6 \\
(25.0-29.9)\end{array}$ & ns \\
\hline Hypertension $\mathrm{n}(\%)$ & $74(68 \%)$ & $14(78 \%)$ & $60(66 \%)$ & ns \\
\hline Diabetes n $(\%)$ & $16(15 \%)$ & $2(11 \%)$ & $14(15 \%)$ & ns \\
\hline Current smoker n $(\%)$ & $16(15 \%)$ & $4(22 \%)$ & $12(13 \%)$ & ns \\
\hline History of smoking $\mathrm{n}(\%)$ & $70(64 \%)$ & $11(61 \%)$ & $59(65 \%)$ & ns \\
\hline Family history of coronary artery disease $\mathrm{n}(\%)$ & $46(42 \%)$ & $10(55 \%)$ & $36(40 \%)$ & ns \\
\hline $\mathrm{LDL}(\mathrm{mg} / \mathrm{dl})$ & $\begin{array}{c}124.0 \\
(93.0-156.0)\end{array}$ & $\begin{array}{c}129.5 \\
(119.0-183.0)\end{array}$ & $\begin{array}{c}121.0 \\
(92.0-152.0)\end{array}$ & ns \\
\hline HDL (mg/dl) & $\begin{array}{c}50.0 \\
(43.0-60.0)\end{array}$ & $\begin{array}{c}48.5 \\
(45.0-60.0)\end{array}$ & $\begin{array}{c}51.0 \\
(43.0-60.0)\end{array}$ & ns \\
\hline $\mathrm{TG}(\mathrm{mg} / \mathrm{dl})$ & $\begin{array}{c}126.0 \\
(93.0-176.0)\end{array}$ & $\begin{array}{c}118.5 \\
(84.0-162.0)\end{array}$ & $\begin{array}{c}130.0 \\
(95.0-176.0)\end{array}$ & ns \\
\hline History of myocardial infarction $\mathrm{n}(\%)$ & $53(49 \%)$ & $8(44 \%)$ & $45(49 \%)$ & ns \\
\hline History of PTCA n (\%) & $16(15 \%)$ & $6(33 \%)$ & $10(11 \%)$ & $<0.02$ \\
\hline History of CABG n (\%) & $6(5 \%)$ & $0(0 \%)$ & $6(7 \%)$ & ns \\
\hline Left ventricular ejection fraction (\%) & $\begin{array}{c}59.0 \\
(45.5-65.0)\end{array}$ & $\begin{array}{c}58.0 \\
(50.0-65.0)\end{array}$ & $\begin{array}{c}59.0 \\
(45.0-65.0)\end{array}$ & ns \\
\hline $2-3$ vessel disease $n(\%)$ & $68(62 \%)$ & $13(72 \%)$ & $55(60 \%)$ & ns \\
\hline Aspirin $\mathrm{n}(\%)$ & $106(97 \%)$ & $17(94 \%)$ & $89(98 \%)$ & ns \\
\hline Statin n (\%) & $108(99 \%)$ & $18(100 \%)$ & $90(99 \%)$ & ns \\
\hline ACE inhibitor $n(\%)$ & $87(80 \%)$ & $14(78 \%)$ & $73(80 \%)$ & ns \\
\hline B-blocker n (\%) & $91(83 \%)$ & $13(72 \%)$ & $78(86 \%)$ & ns \\
\hline Calcium antagonist $\mathrm{n}(\%)$ & $27(25 \%)$ & $6(33 \%)$ & $21(23 \%)$ & ns \\
\hline
\end{tabular}

Statistical analysis. Use of the Shapiro-Wilk test demonstrated that the investigated variables were not normally distributed. Therefore, continuous results were reported as median values and interquartile ranges. Comparisons between groups were analysed with the Mann-Whitney unpaired rank sum test, whereas the Wilcoxon matched-paired rank sum test was used for comparisons within the groups. Correlations were tested with the Spearman rank correlation test. The KaplanMeier method was applied for the visual presentation of clinical restenosis incidence. Survival curves were compared with the log-rank test. Independent prognostic factors of the primary end point occurrence were determined with the Cox proportional hazard model. Relations between the investigated variables and the likelihood of restenosis were estimated with the use of odds ratios (OR) and their 95\% confidence intervals $(95 \% \mathrm{CI})$. Qualitative data were assessed with the usage of the Chi-squared test with Yates correction or the Fisher exact test when appropriate. p values $<0.05$ were considered statistically significant; values $\geq 0.05$ are indicated with the abbreviation, ns (not significant). All computations were carried out with Statistica, version 7.1 (StatSoft, Tulsa, OK, USA).

\section{Results}

Immediate and long-term outcomes. An optimal immediate outcome of stenting was achieved in 105 subjects (96\%), without any differences between those with and without 
Table II. Characteristics of the procedures.

\begin{tabular}{|c|c|c|c|c|}
\hline Parameter & $\begin{array}{l}\text { The entire cohort } \\
\qquad(\mathrm{n}=109)\end{array}$ & $\begin{array}{l}\text { Restenosis }(+) \\
\quad(n=18)\end{array}$ & $\begin{array}{l}\text { Restenosis }(-) \\
\quad(n=91)\end{array}$ & $\mathrm{p}$ \\
\hline Optimal outcome of PTCA n (\%) & $105(96 \%)$ & $17(94 \%)$ & $88(97 \%)$ & ns \\
\hline \multicolumn{5}{|l|}{ Number of implanted stents } \\
\hline 1 & $89(82 \%)$ & $16(89 \%)$ & $73(80 \%)$ & \\
\hline 2 & $17(15 \%)$ & $1(5.5 \%)$ & $16(18 \%)$ & ns \\
\hline 3 & $3(3 \%)$ & $1(5.5 \%)$ & $2(2 \%)$ & \\
\hline Length of stent/stents (mm) & $\begin{array}{c}18.0 \\
(13.0-23.0)\end{array}$ & $\begin{array}{c}19.0 \\
(15.0-25.0)\end{array}$ & $\begin{array}{c}18.0 \\
(13.0-23.0)\end{array}$ & ns \\
\hline Diameter of stent/stents (mm) & $\begin{array}{c}3.0 \\
(2.5-3.25)\end{array}$ & $\begin{array}{c}3.0 \\
(2.5-3.0)\end{array}$ & $\begin{array}{c}3.0 \\
(2.5-3.5)\end{array}$ & ns \\
\hline \multicolumn{5}{|l|}{ Type of contrast medium } \\
\hline Iodixanol & $28(26 \%)$ & $3(17 \%)$ & $25(27 \%)$ & \\
\hline Iopromide & $11(10 \%)$ & $3(17 \%)$ & $8(9 \%)$ & ns \\
\hline Iomeprol & $70(64 \%)$ & $12(66 \%)$ & $58(64 \%)$ & \\
\hline Volume of contrast medium (ml) & $\begin{array}{c}170.0 \\
(130.0-230.0)\end{array}$ & $\begin{array}{c}190.0 \\
(150.0-230.0)\end{array}$ & $\begin{array}{c}160.0 \\
(130.0-230.0)\end{array}$ & ns \\
\hline Maximal implantation pressure (atmospheres) & $\begin{array}{c}14.0 \\
(12.0-16.0)\end{array}$ & $\begin{array}{c}12.0 \\
(10.0-15.0)\end{array}$ & $\begin{array}{c}14.0 \\
(12.0-16.0)\end{array}$ & ns \\
\hline
\end{tabular}

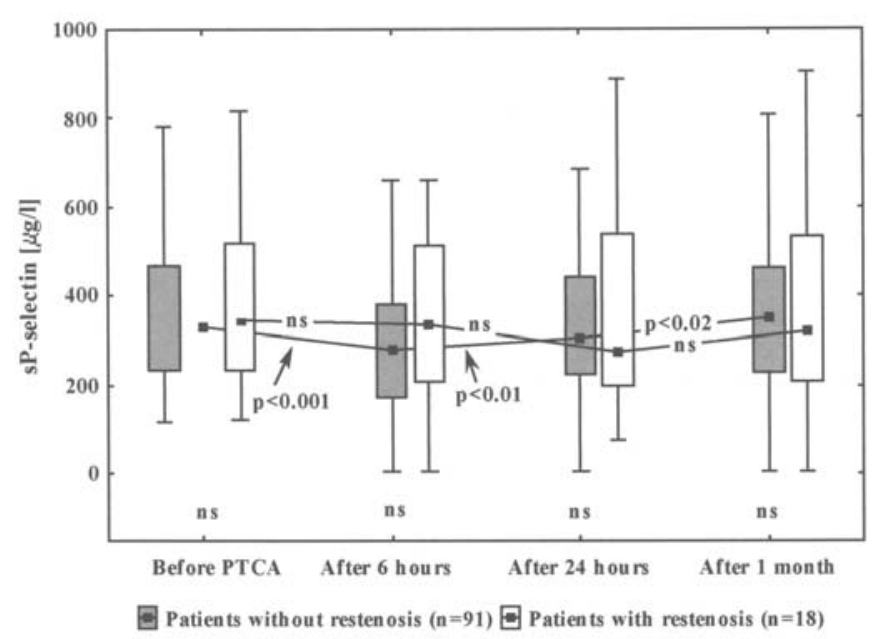

Figure 1. Periprocedural sP-selectin levels as medians, interquartile ranges and ranges in patients with and without clinical restenosis. $\mathrm{p}$ values are related to the differences between groups at the same measuring point and to the differences within the groups between subsequent measurements.

clinical restenosis (Table II). During a 1-year follow-up, we noted 1 cardiac death (1\%) 6 months after PTCA. Two months after the intervention this patient was readmitted to our department due to a recurrence of angina. Coronary angiography revealed a diffuse in-stent restenosis that was treated with balloon angioplasty. At 1 year nonfatal myocardial infarction occurred in 6 patients $(5.5 \%)$, including 1 case $(1 \%)$ of procedure-related myocardial infarction. Another

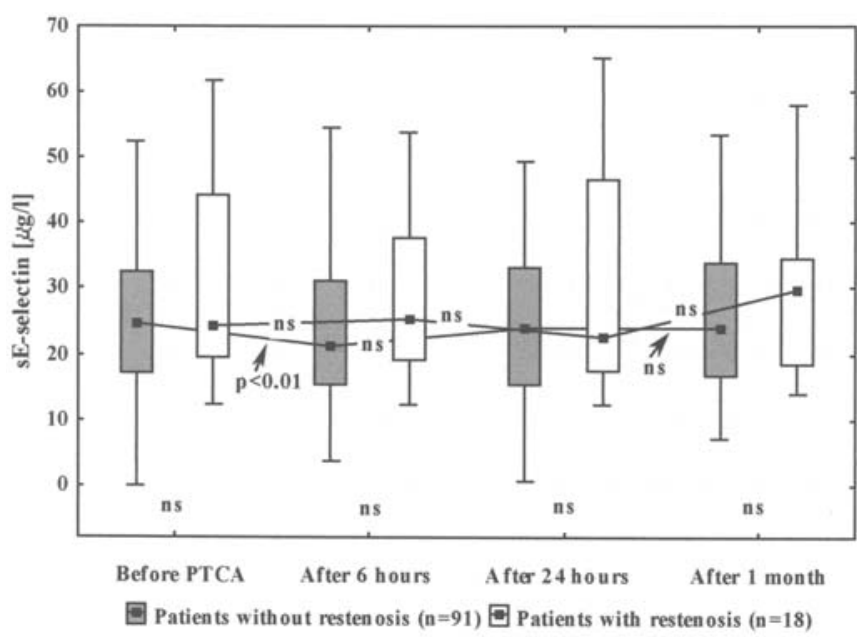

Figure 2. Periprocedural sE-selectin levels as medians, interquartile ranges and ranges in patients with and without clinical restenosis. p values are related to the differences between groups at the same measuring point and to the differences within the groups between subsequent measurements.

subject $(1 \%)$ experienced myocardial infarction caused by occlusive in-stent restenosis. Thirty-five study participants (32\%) underwent repeated coronary angiography and 1 person $(1 \%)$ refused permission for the examination despite existing indications. Angiographic restenosis was confirmed in 18 patients $(16.5 \%)$, while stenosis concerning another lesion other than being dilated at the index procedure was diagnosed in 9 cases $(8 \%)$. Focal and diffuse patterns of in- 


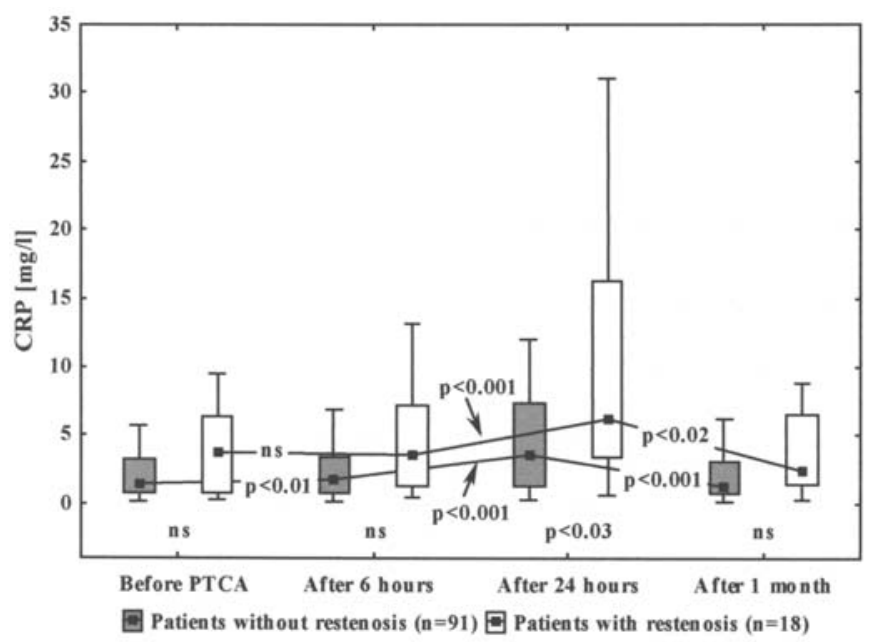

Figure 3. Periprocedural CRP levels as medians, interquartile ranges and ranges in patients with and without clinical restenosis. $p$ values are related to the differences between groups at the same measuring point and to the differences within the groups between subsequent measurements.

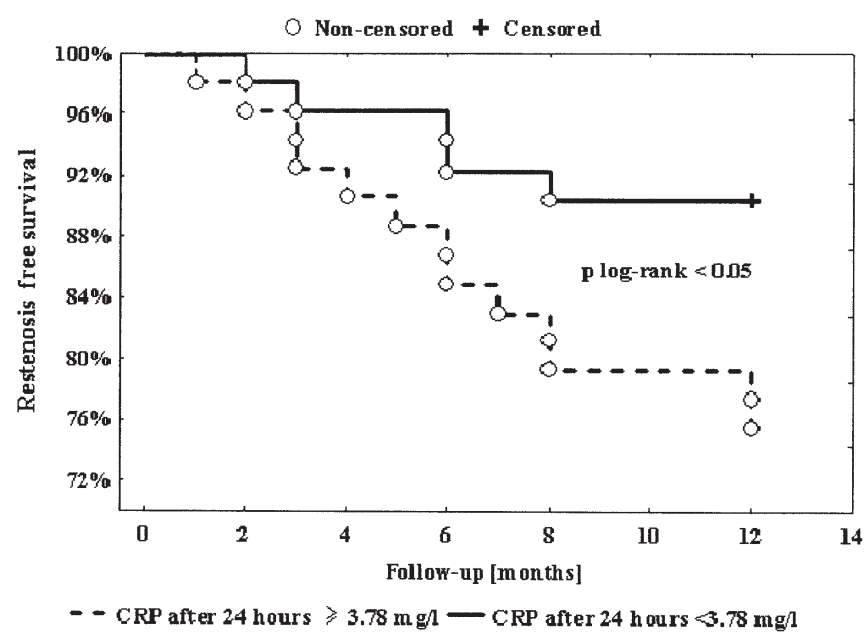

Figure 4. The incidence of clinical restenosis in relation to the CRP level $24 \mathrm{~h}$ after the intervention.

stent restenosis were present in $9(50 \%)$ and 4 subjects $(22 \%)$, respectively. Also, in 4 individuals $(22 \%)$ in-stent restenosis was classified as proliferative, and 1 person $(6 \%)$ developed an occlusive vessel re-narrowing. Among 18 patients with in-stent restenosis, 14 (78\%) were treated with PTCA, 3 (17\%) underwent coronary artery bypass grafting, and one patient $(5 \%)$ did not give permission for cardiosurgical revascularization and was managed conservatively.

Kinetics of biomarkers. Concentrations of sP-selectin and sE-selectin did not differ between patients with and without clinical restenosis at any measuring point. In the latter group, a decrease in sP- and sE-selectin levels was observed $6 \mathrm{~h}$ after stenting (Figs. 1 and 2). An inflammatory response assessed as an increase in CRP level with peak values at $24 \mathrm{~h}$ was noted in the entire population. However, it was significantly more pronounced in the restenosis group (Fig. 3).
To note, baseline CRP levels and peak CRP values at $24 \mathrm{~h}$ were correlated (all patients, $\mathrm{R}_{\mathrm{S}}=0.76, \mathrm{p}<0.000001$; patients with restenosis, $\mathrm{R}_{\mathrm{S}}=0.68, \mathrm{p}<0.002$; and patients without restenosis, $\left.\mathrm{R}_{\mathrm{S}}=0.79, \mathrm{p}<0.000001\right)$.

Predictors of clinical restenosis. Patients who developed clinical restenosis were more likely to have a history of nontarget PTCA when compared to the group without restenosis (Table I). Univariate analysis failed to identify $\mathrm{sP}$ - and sE-selectin levels at any measuring points or differences between measurements as prognostic factors of the primary end point. CRP concentrations at $24 \mathrm{~h}$ below the median and lack of previous coronary angioplasty were associated with remarkably longer restenosis-free survival as illustrated in Figs. 4 and 5. The application of the Cox proportional hazard model revealed a high CRP level $24 \mathrm{~h}$ after stenting and the history of coronary angioplasty concerning a nontarget lesion to be the only independent predictors of clinical restenosis as indicated in Table III. In subjects with prior nontarget PTCA $(n=16)$, in comparison to those treated interventionally for the first time $(n=93)$, a history of myocardial infarction ( $87 \%$ vs $42 \%, \mathrm{p}<0.003)$, previous CABG procedure ( $25 \%$ vs $2 \%, \mathrm{p}<0.005)$, depressed left ventricular ejection fraction $(50 \%$ vs $60 \%, \mathrm{p}<0.0001)$ and multi-vessel disease ( $81 \%$ vs $59 \%$ ) were more prevalent, but in the last case statistical significance was not obtained.

\section{Discussion}

Despite consistent basic scientific research suggesting a casual relation between the expression of selectins at the site of PTCA-induced arterial injury and subsequent neointimal formation, the obtained results do not support the initial concept on the value of sP- and sE-selectin evaluation in peripheral venous blood in the prediction of restenosis. Data derived from animal models must be interpreted with caution. Pre-clinical models are just preliminary tools that can help generate ideas that must be verified in humans. In addition to profound inter-species differences, angioplasty procedures in animals are usually performed with a balloon on atherosclerosis-free peripheral vessels.

According to our knowledge, ours is the largest of few studies testing the hypothesis on the prognostic value of periprocedural soluble $\mathrm{P}$ - and E-selectin levels in a homogenous population of stable angina patients treated in line with contemporary pharmacological and interventional standards. The limitations of completed trials include the use of balloon angioplasty as a preferred treatment method, a considerable proportion of patients with unstable angina, the underutilization of evidence-based medical therapies, small sample size, and lack of clinical follow-up. In addition, the coronary sinus blood sampling performed by some researchers precludes the implementation of their findings into daily practice and makes impossible any comparison to our material. Thus, conclusions formulated on the basis of previous studies do not necessarily apply to the present clinical setting.

Direct comparisons of studies might be affected by the profound differences between vascular responses to balloonand stent-triggered injuries. Coronary stenting resulted in a 
Table III. Independent predictors of clinical restenosis in the Cox proportional hazard model.

\begin{tabular}{|c|c|c|c|c|c|}
\hline Variable & Variant & $\mathrm{n}$ & OR & $95 \% \mathrm{CI}$ & $\mathrm{p}$ \\
\hline \multirow[t]{3}{*}{$\mathrm{CRP}$ at $24 \mathrm{~h}$ after PTCA } & Continuous variable & 109 & 1.05 & $1.01-1.09$ & $<0.01$ \\
\hline & $\begin{array}{l}\mathrm{CRP} \text { at } 24 \mathrm{~h} \text { after PTCA } \\
\geq \text { median }(\geq 3.78 \mathrm{mg} / \mathrm{l})\end{array}$ & 55 & 3.02 & $1.04-8.74$ & $<0.05$ \\
\hline & $\begin{array}{l}\text { CRP at } 24 \mathrm{~h} \text { after PTCA } \\
<\text { median }(<3.78 \mathrm{mg} / \mathrm{l})\end{array}$ & 54 & 1.00 & - & - \\
\hline \multirow[t]{2}{*}{ Prior PTCA of another stenosis } & True & 16 & 3.52 & $1.32-9.40$ & $<0.02$ \\
\hline & False & 93 & 1.00 & - & - \\
\hline
\end{tabular}

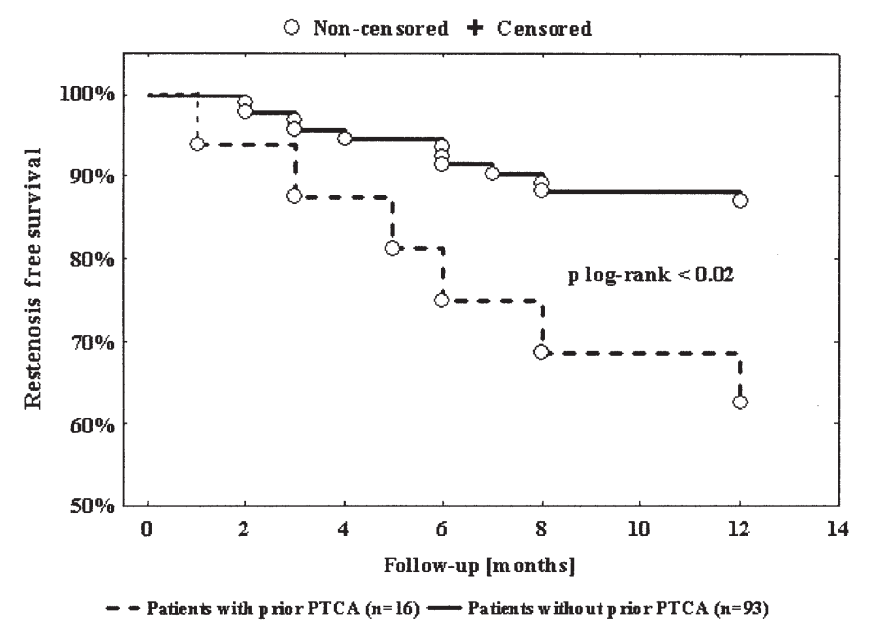

Figure 5. The incidence of clinical restenosis in patients with and without prior angioplasty concerning another stenosis.

larger initial lumen gain and more efficient prevention of remodelling with coexisting greater neointimal growth (21). Inoue et al demonstrated a substantially higher neutrophile CD11b expression in patients undergoing stent implantation versus patients undergoing balloon angioplasty (22). Additionally, in an animal model of stented artery an abundant macrophage recruitment within the neointima contrary to neutrophil infiltration preceding neointimal thickening in balloon-injured artery was observed $(23,24)$. Heparin use diminished macrophage accumulation in the stented vessel and reduced overall neointimal growth (23). Moreover, the inhibition of neutrophil infiltration in ballooninjured artery successfully limited smooth muscle proliferation (24).

The composition of culprit plaques differs substantially between stable angina and acute coronary syndromes including 4-fold higher intimal macrophage content (25) and 2.3-fold larger tissue factor content (26) in the latter group. In unstable angina patients undergoing coronary atherectomy, the intensity of macrophage infiltration predicted vessel re-narrowing (27). Vulnerable plaques typical for acute coronary syndromes are also characterized by a large lipid-rich core, a thin fibrous cap containing few smooth muscle cells, vasa vasorum neovascularization, adventitial inflammation and outward remodeling (28).

Most of the drugs proven to prolong life in patients with coronary artery disease possess pleiotropic effects including anti-inflammatory properties. Patients recruited into our study were treated on the basis of current guidelines. The overwhelming majority of them were given statin, aspirin, Bblockers, angiotensin-converting enzyme inhibitor and ticlopidine. Statins diminish sP-selectin and sE-selectin levels as well as CRP concentration (29,30). Moreover, the magnitude of reduction is inversely correlated with the progression of coronary atherosclerosis (29). The evidence for the impact of statins on restenosis due to conflicting results and limitations of the studies remains less convincing (31-33). In LDL receptor-deficient mice fed a high-fat diet compared with control mice, low-dose aspirin induced a significant decrease in circulating levels of soluble intercellular adhesion molecule-1 (sICAM-1), monocyte chemoattractant protein- 1 , tumor necrosis factor- $\alpha$, and interleukin$12 \mathrm{p} 40$ and lowered the activity of nuclear factor $\mathrm{\kappa B}$, without affecting lipid levels. Low-dose aspirin also significantly reduced both the extent of atherosclerosis and the amount of macrophages within plaques (34). In a physicians' health study comparing an 8-year clinical outcome in 543 apparently healthy men randomly assigned to receive aspirin or placebo, the use of aspirin was associated with significant reductions in the risk of myocardial infarction $(55.7 \%, \mathrm{p}=0.02)$ among men in the highest quartile of CRP levels but with only small, nonsignificant reductions among those in the lowest quartile of CRP values (13.9\%, $\mathrm{p}=0.77$ ) (35). Among patients with a first Q-wave acute myocardial infarction, therapy with $\beta$-blockers within $24 \mathrm{~h}$ of the onset of symptoms resulted in a decreased peak CRP level and a lower in-hospital cardiac mortality, despite similar maximal creatine phosphokinase activity (36). In a prospective registry of 4840 patients undergoing percutaneous coronary revascularization, ß-blockers conferred a protective effect against clinical restenosis (37). It is also suggested that the beneficial effect on circulating adhesion molecules, monocyte chemotactic protein-1 (38) and CRP levels (39) may contribute to cardiovascular risk reduction mediated by angiotensin-converting enzyme inhibitors aside from a blood pressure lowering 
effect. Clopidogrel, a thienopyridine derivate similar to ticlopidine used in our study, attenuated both PTCA-induced increase in serum CRP level (40) and P-selectin expression on platelets (41).

There is conflicting evidence with regard to the relationship of $\mathrm{sP}$ - and sE-selectin levels in the blood collected from coronary sinus and superficial peripheral veins $(6,42)$. Although we cannot exclude that only levels of selectins in the coronary circulation are of prognostic value, the benefits of coronary sinus caniulation do not seem to outweigh the additional risk of complications.

Kurz and colleagues observed a significant increase in sP-selectin and soluble L-selectin (sL-selectin) levels in 30 patients in peripheral venous blood $24 \mathrm{~h}$ after elective balloon angioplasty. They also found a positive correlation between the number of dilatations and the rise in these parameters. The concentration of SICAM-1 was stable throughout the study period. In 15 subjects who underwent elective coronary angiography without PTCA the serum concentrations of analysed mediators did not change significantly (43). The group led by Inoue reported elevated concentrations of sP-selectin, sL-selectin and sICAM-1 $48 \mathrm{~h}$ after PTCA in the coronary sinus blood samples of 25 stable angina patients treated with balloon angioplasty. These changes were not observed in the peripheral blood samples. The sE-selectin level did not change after angioplasty. The application of multiple regression showed that the late loss index obtained from quantitative coronary angiography was correlated with the changes in sP-selectin $(\mathrm{r}=0.26, \mathrm{p}<0.05)$, sL-selectin $(\mathrm{r}=0.28$, $\mathrm{p}<0.05)$ and ICAM-1 $(\mathrm{r}=0.31, \mathrm{p}<0.05)$ in the coronary sinus blood samples $48 \mathrm{~h}$ after angioplasty. All patients were on therapy with aspirin, nifedipine, dipyridamole and isosorbide dinitrate (42). Sainani and Maru analysed 46 stable angina subjects undergoing balloon angioplasty $(n=25)$ or coronary stenting $(n=21)$. Baseline sE-selectin levels assessed in peripheral blood predicted clinical restenosis. However this study provides no information as to how the patients were managed pharmacologically. The high clinical restenosis rate (43\%) in this study must be also stressed (44). Other authors investigating stable angina subjects treated with balloon angioplasty $(n=20)$ or stenting $(n=41)$ concluded, on the basis of posthoc analysis, that substantial increase in sE-selectin levels $3 \mathrm{~h}$ after the intervention that persisted until $24 \mathrm{~h}$ might predict the development of restenosis. However, in the primary analysis the sE-selectin levels of the patients with and without restenosis were similar at each of the three measurements and significantly increased after the intervention both in the balloon angioplasty and stenting group. Information on the background therapy is limited to administration of aspirin and ticlopidine (45). Cipollone et al measured significantly higher sE-selectin, sICAM-1 and soluble vascular cell adhesion molecule-1 (sVCAM-1) values at $1,5,15$ and 180 days in subjects with angiographic restenosis originally treated with balloon angioplasty due to stable $(n=22)$ and unstable $(n=48)$ coronary disease $(46)$. Vandoni et al demonstrated a lack of difference in sE-selectin levels before the intervention and after 1 month between groups with $(n=4)$ and without $(n=21)$ restenosis who initially underwent elective single vessel stenting. Similarly, in this study, for patients treated with roxithromycin $(300 \mathrm{mg} /$ once daily), the concentration of sE-selectin did not differ in relation to the incidence of restenosis. Antibiotic treatment did not influence circulating sE-selectin levels (47). Rauchhaus and colleagues examining 193 patients proved that the E-selectin 128Arg allele may serve as a risk factor for the development of angiographic restenosis after balloon angioplasty. Laboratory assays possible in 32 subjects with restenosis and in 37 people without vessel re-narrowing revealed no difference in the baseline sE-selectin concentration between groups. The study did not document whether the participants were hospitalised for stable or unstable angina and how many of them were on statins (48). Finally, after an analysis of 40 patients treated with elective coronary stenting, researchers concluded that sP-selectin levels decreased significantly $48 \mathrm{~h}$ after PTCA exclusively in subjects without restenosis while concentrations of sE-selectin showed a reduction at $48 \mathrm{~h}$ in the entire population. All patients received aspirin, clopidogrel, statins, $\beta$-blockers and angiotensin-converting enzyme inhibitors (49).

Generally, there is a tendency towards a lower increase or even a decrease in the postprocedural selectin level in more recent studies with patients treated predominantly with stenting on optimal medical therapy. We hypothesize that a transient fall in the soluble selectin level in the group without restenosis may reflect their binding to the target receptors on the surface of leukocytes, platelets and endothelial cells thus preventing cellular interaction between these cell types involving surface selectins $(6,50)$. Soluble forms of selectins would thus appear to be endogenous antithrombotic and antiinflammatory molecules (6). Leukocyte and platelet activation occurring across a dilated artery segment up-regulated the expression of surface selectins (51) and led to a rise in soluble selectins between 6 and $24 \mathrm{~h}$ after the intervention.

The negative result of our trial does not mean that the administration of P- or E-selectin antagonists will be ineffective in restenosis prevention. However, future projects need to be conducted. So far, despite the established effectiveness in canine and porcine models $(52,53)$, infusion of recombinant P-selectin glycoprotein ligand-immunoglobulin failed to facilitate tissue salvage when given in combination with thrombolysis in the setting of ST-elevation myocardial infarction (54).

The role of C-reactive protein has been extensively investigated in preventive cardiology. Our data emphasize the clinical importance of the stenting-induced systemic inflammatory response. In our study, CRP levels equal or above the median at $24 \mathrm{~h}$ were associated with a 3 -fold higher risk of restenosis when compared to CRP concentrations below the median. This observation corresponds with earlier publications $(18,20)$. In the largest completed trial assessing the value of periprocedural CRP evaluation in a series of 1800 consecutive patients with stable and unstable coronary artery disease treated with stenting, the magnitude of the inflammatory response determined the risk of angiographic as well as clinical restenosis (19). Therefore, an antiinflammatory treatment in patients after PTCA with an extensive and prolonged inflammatory response might be of high clinical importance. In the IMPRESS study of patients with persistent high CRP levels $(>5 \mathrm{mg} / \mathrm{l})$ at $72 \mathrm{~h}$ after 
successful coronary stenting, oral prednisone therapy was introduced for 45 days and resulted in a noticeable reduction in clinical events and the angiographic restenosis rate (55). Postprocedural CRP rise in patients undergoing PTCA may reflect a broad spectrum of pathomechanisms. Suggested nonspecific stimuli include mechanical disruption of atherosclerotic plaque, arterial wall injury, myocardial necrosis due to distal embolisation, release of inflammatory and chemoattractant factors followed by leukocyte and platelet activation along with the ischemia-reperfusion cycle induced by multiple balloon inflations $(56,57)$. However, uncomplicated coronary angiography also triggers an inflammatory response, similar in its magnitude to that induced in stable angina patients undergoing coronary stenting (58). For patients undergoing coronary angiography the triggering factors may vary from contrast agent-mediated endothelial damage, local inflammatory reaction in the area of femoral artery puncture, groin haematoma to arterial wall injuries and atherosclerotic plaque destabilisation due to guide wire and catheter manipulation in the aorta $(58,59)$.

According to a search in the Medline database, a second study reported an increased restenosis incidence in patients with a history of PTCA concerning another stenosis. We corroborate the results found by Arjomand et al, who, investigating a population of 9745 subjects enrolled in the PRESTO trial, noticed significantly more major adverse cardiac events in patients with previous PTCA of either the target or nontarget lesion when compared to participants undergoing coronary angioplasty for the first time. The difference was mainly driven by higher rates of repeat revascularization (60). We speculate that the presence of risk factors common for both restenosis and atherosclerosis progression, such as low-grade inflammation or genetic propensity, may at least partially elucidate our observation. In our study population, the history of myocardial infarction and prior coronary artery bypass grafting, depressed left ventricular ejection fraction and multi-vessel disease were more frequent in patients with prior nontarget PTCA.

Our results need to be validated in a larger cohort of patients. They refer only to stable angina subjects treated with bare metal stenting. Additionally, the restenosis rate evaluated according to the study protocol on the basis of the exercise treadmill test and spontaneous chest pain recurrence might be underestimated. However, ischemia-driven target vessel revascularizations reflecting clinical restenosis in our study is widely accepted, and as routine practice, control coronary angiography is not recommended except for selected high-risk groups $(61,62)$.

In conclusion, our data indicate that periprocedural evaluation of sP-selectin and sE-selectin in peripheral venous blood in patients undergoing elective coronary stenting does not provide prognostic information in terms of clinical restenosis prediction. Multivariate analysis revealed a postprocedural increase in CRP level and the history of coronary angioplasty concerning nontarget stenosis to be independent predictors of lesion re-narrowing.

\section{References}

1. Al Suwaidi J, Berger PB and Holmes DR Jr: Coronary artery stents. JAMA 284: 1828-1836, 2000.
2. Joner M, Finn AV, Farb A, et al: Pathology of drug-eluting stents in humans: delayed healing and late thrombotic risk. J Am Coll Cardiol 48: 193-202, 2006.

3. Pfisterer ME, Kaiser CA, Bader F, Brunner-La Rocca HP, Bonetti PO and Buser PT: Late clinical events related to late stent thrombosis after stopping clopidogrel: prospective randomized comparison between drug-eluting versus bare-metal stenting. In: Abstracts from the American College of Cardiology 55th Annual Scientific Session. American College of Cardiology, abstract 422-11, 2006.

4. Kaiser C, Brunner-La Rocca HP, Buser PT, et al: Incremental cost-effectiveness of drug-eluting stents compared with a thirdgeneration bare-metal stent in a real-world setting: randomised Basel Stent Kosten Effektivitats Trial (BASKET). Lancet 366: 921-929, 2005.

5. Diacovo TG, Roth SJ, Buccola JM, Bainton DF and Springer TA: Neutrophil rolling, arrest, and transmigration across activated, surface-adherent platelets via sequential action of P-selectin and the beta 2-integrin CD11b/CD18. Blood 88: 146-157, 1996.

6. Mulvihill NT, Foley JB, Walsh MA and Crean PA: Relationship between intracoronary and peripheral expression of soluble cell adhesion molecules. Int J Cardiol 77: 223-229, 2001.

7. Johnston GI, Bliss GA, Newman PJ and McEver RP: Structure of the human gene encoding granule membrane protein-140, a member of the selectin family of adhesion receptors for leukocytes. J Biol Chem 265: 21381-21385, 1990.

8. Blann AD and McCollum CN: Increased soluble P-selectin in peripheral artery disease: a new marker for the progression of atherosclerosis. Thromb Haemost 80: 1031-1032, 1998.

9. Blankenberg S, Rupprecht HJ, Bickel C, Peetz D, Hafner G, Tiret L and Meyer J: Circulating cell adhesion molecules and death in patients with coronary artery disease. Circulation 104: 1336-1342, 2001

10. Blann AD, Faragher EB and McCollum CN: Increased soluble P-selectin following myocardial infarction: a new marker for the progression of atherosclerosis. Blood Coagul Fibrinolysis 8: 383-390, 1997.

11. Ridker PM, Buring JE and Rifai N: Soluble P-selectin and the risk of future cardiovascular events. Circulation 103: 491-495, 2001.

12. Hayashi S, Watanabe N, Nakazawa K, et al: Roles of P-selectin in inflammation, neointimal formation, and vascular remodeling in balloon-injured rat carotid arteries. Circulation 102: 1710-1717, 2000.

13. Zhou Z, Penn MS, Forudi F, et al: Administration of recombinant $\mathrm{P}$-selectin glycoprotein ligand $\mathrm{Fc}$ fusion protein suppresses inflammation and neointimal formation in Zucker diabetic rat model. Arterioscler Thromb Vasc Biol 22: 1598-1603, 2002.

14. Manka D, Collins RG, Ley K, Beaudet AL and Sarembock IJ: Absence of p-selectin, but not intercellular adhesion molecule-1, attenuates neointimal growth after arterial injury in apolipoprotein e-deficient mice. Circulation 103: 1000-1005, 2001.

15. Kumar A, Hoover JL, Simmons CA, Lindner V and Shebuski RJ: Remodeling and neointimal formation in the carotid artery of normal and P-selectin-deficient mice. Circulation 96: 4333-4342, 1997.

16. Akers DL, Lefer DJ, Chen IL, et al: Effect of short-term treatment with a monoclonal antibody to P-selectin on balloon catheter-induced: intimal hyperplasia, re-endothelialization, and attenuation of endothelial-dependent relaxation. Mol Cell Biochem 176: 13-20, 1997.

17. Gotoh R, Suzuki J, Kosuge H, Kakuta T, Sakamoto S, Yoshida M and Isobe M: E-selectin blockade decreases adventitial inflammation and attenuates intimal hyperplasia in rat carotid arteries after balloon injury. Arterioscler Thromb Vasc Biol 24: 2063-2068, 2004.

18. Krzewina-Kowalska A, Kubica J, Kozinski M, et al: Selected acute phase proteins in patients undergoing coronary angioplasty. Folia Cardiol 10: 733-742, 2003.

19. Dibra A, Mehilli J, Braun S, et al: Inflammatory response after intervention assessed by serial C-reactive protein measurements correlates with restenosis in patients treated with coronary stenting. Am Heart J 150: 344-350, 2005.

20. Kubica J, Kozinski M, Krzewina-Kowalska A, et al: Combined periprocedural evaluation of CRP and TNF- $\alpha$ enhances the prediction of clinical restenosis and major adverse cardiac events in patients undergoing percutaneous coronary interventions. Int J Mol Med 16: 173-180, 2005. 
21. Welt FG and Rogers C: Inflammation and restenosis in the stent era. Arterioscler Thromb Vasc Biol 22: 1769-1776, 2002.

22. Inoue T, Sohma R, Miyazaki T, Iwasaki Y, Yaguchi I and Morooka S: Comparison of activation process of platelets and neutrophils after coronary stent implantation versus balloon angioplasty for stable angina pectoris. Am J Cardiol 86: 1057-1062, 2000.

23. Rogers C, Welt FG, Karnovsky MJ and Edelman ER: Monocyte recruitment and neointimal hyperplasia in rabbits. Coupled inhibitory effects of heparin. Arterioscler Thromb Vasc Biol 16: 1312-1318, 1996.

24. Welt FG, Edelman ER, Simon DI and Rogers C: Neutrophil, not macrophage, infiltration precedes neointimal thickening in balloon-injured arteries. Arterioscler Thromb Vasc Biol 20: 2553-2558, 2000

25. Moreno PR, Falk E, Palacios IF, Newell JB, Fuster V and Fallon JT: Macrophage infiltration in acute coronary syndromes. Implications for plaque rupture. Circulation 90: 775-778, 1994.

26. Moreno PR, Bernardi VH, Lopez-Cuellar J, et al: Macrophages, smooth muscle cells, and tissue factor in unstable angina. Implications for cell-mediated thrombogenicity in acute coronary syndromes. Circulation 94: 3090-3097, 1996.

27. Moreno PR, Bernardi VH, Lopez-Cuellar J, et al: Macrophage infiltration predicts restenosis after coronary intervention in patients with unstable angina. Circulation 94: 3098-3102, 1996.

28. Falk E: Pathogenesis of atherosclerosis. J Am Coll Cardiol 47 (suppl 8): C7-C12, 2006.

29. Marschang P, Friedrich GJ, Ditlbacher H, et al: Reduction of soluble P-selectin by statins is inversely correlated with the progression of coronary artery disease. Int J Cardiol 106: 183-190, 2006.

30. Hernandez C, Lecube A, Barbera G, Chacon P, Lima J and Simo R: Effects of hypolipidemic treatment on serum markers of vascular inflammation in dyslipidemic men. Med Sci Monit 9: CR114-CR119, 2003

31. Serruys PW, Foley DP, Jackson G, et al: A randomized placebo-controlled trial of fluvastatin for prevention of restenosis after successful coronary balloon angioplasty; final results of the fluvastatin angiographic restenosis (FLARE) trial. Eur Heart J 20: 58-69, 1999.

32. Walter DH, Schachinger V, Elsner M, Mach S, Dimmeler S, Auch-Schwelk W and Zeiher AM: Statin therapy is associated with reduced restenosis rates after coronary stent implantation in carriers of the $\mathrm{Pl}(\mathrm{A} 2)$ allele of the platelet glycoprotein IIIa gene. Eur Heart J 22: 587-595, 2001.

33. Walter DH, Schachinger V, Elsner M, Mach S, Auch-Schwelk W and Zeiher AM: Effect of statin therapy on restenosis after coronary stent implantation. Am J Cardiol 85: 962-968, 2000

34. Cyrus T, Sung S, Zhao L, Funk CD, Tang S and Pratico D: Effect of low-dose aspirin on vascular inflammation, plaque stability, and atherogenesis in low-density lipoprotein receptordeficient mice. Circulation 106: 1282-1287, 2002.

35. Ridker PM, Cushman M, Stampfer MJ, Tracy RP and Hennekens CH: Inflammation, aspirin, and the risk of cardiovascular disease in apparently healthy men. N Engl J Med 336: 973-979, 1997.

36. Anzai T, Yoshikawa T, Takahashi T, et al: Early use of betablockers is associated with attenuation of serum C-reactive protein elevation and favorable short-term prognosis after acute myocardial infarction. Cardiology 99: 47-53, 2003.

37. Jackson JD, Muhlestein JB, Bunch TJ, et al: Beta-blockers reduce the incidence of clinical restenosis: prospective study of 4840 patients undergoing percutaneous coronary revascularization. Am Heart J 145: 875-881, 2003.

38. Jilma B, Li-Saw-Hee FL, Wagner OF, Beevers DG and Lip GY: Effects of enalapril and losartan on circulating adhesion molecules and monocyte chemotactic protein-1. Clin Sci 103: 131-136, 2002

39. Mitrovic V, Klein HH, Krekel N, et al: Influence of the angiotensin converting enzyme inhibitor ramipril on highsensitivity C-reactive protein (hs-CRP) in patients with documented atherosclerosis. Z Kardiol 94: 336-342, 2005.

40. Vivekananthan DP, Bhatt DL, Chew DP, et al: Effect of clopidogrel pretreatment on periprocedural rise in C-reactive protein after percutaneous coronary intervention. Am J Cardiol 94: 358-360, 2004.

41. Quinn MJ, Bhatt DL, Zidar F, et al: Effect of clopidogrel pretreatment on inflammatory marker expression in patients undergoing percutaneous coronary intervention. Am. J Cardiol 93: 679-684, 2004
42. Inoue $\mathrm{T}$, Hoshi $\mathrm{K}$, Yaguchi I, Iwasaki Y, Takayanagi K and Morooka S: Serum levels of circulating adhesion molecules after coronary angioplasty. Cardiology 91: 236-242, 1999.

43. Kurz RW, Graf B, Gremmel F, Wurnig C and Stockenhuber F: Increased serum concentrations of adhesion molecules after coronary angioplasty. Clin Sci 87: 627-633, 1994.

44. Sainani GS and Maru VG: The endothelial leukocyte adhesion molecule. Role in coronary artery disease. Acta Cardiol 60: 501-507, 2005.

45. Kilickap M, Tutar E, Aydintug O, Pamir G, Erol C, Tutkak H and Oral D: Increase in soluble E-selectin level after PTCA and stent implantation: a potential marker of restenosis. Int J Cardiol 93: $13-18,2004$

46. Cipollone F, Ferri C, Desideri G, et al: Preprocedural level of soluble CD40L is predictive of enhanced inflammatory response and restenosis after coronary angioplasty. Circulation 108: 2776-2782, 2003.

47. Vandoni P, Morelli B, Lazzati L, et al: Effect of a short antibiotic treatment with roxithromycin on circulating adhesion molecules after coronary stenting: a single-center pilot trial. Ital Heart J 5: 667-672, 2004.

48. Rauchhaus M, Gross M, Schulz S, et al: The E-selectin SER128ARG gene polymorphism and restenosis after successful coronary angioplasty. Int J Cardiol 83: 249-257, 2002.

49. Schulze PC, Kluge E, Schuler G and Lauer B: Periprocedural kinetics in serum levels of cytokines and adhesion molecules in elective PTCA and stent implantation: impact on restenosis. Arterioscler Thromb Vasc Biol 22: 2105-2107, 2002.

50. Gamble JR, Skinner MP, Berndt MC and Vadas MA Prevention of activated neutrophil adhesion to endothelium by soluble adhesion protein GMP140. Science 249: 414-417, 1990.

51. Serrano CV Jr, Ramires JA, Venturinelli M, et al: Coronary angioplasty results in leukocyte and platelet activation with adhesion molecule expression. Evidence of inflammatory responses in coronary angioplasty. J Am Coll Cardiol 29: 1276-1283, 1997

52. Wang K, Zhou X, Zhou Z, et al: Recombinant soluble P-selectin glycoprotein ligand-Ig (rPSGL-Ig) attenuates infarct size and myeloperoxidase activity in a canine model of ischemiareperfusion. Thromb Haemost 88: 149-154, 2002

53. Hansen A, Kumar A, Wolf D, et al: Evaluation of cardioprotective effects of recombinant soluble P-selectin glycoprotein ligand-immunoglobulin in myocardial ischemiareperfusion injury by real-time myocardial contrast echocardiography. J Am Coll Cardiol 44: 887-891, 2004.

54. Mertens P, Maes A, Nuyts J, et al: Recombinant P-selectin glycoprotein ligand-immunoglobulin, a P-selectin antagonist, as an adjunct to thrombolysis in acute myocardial infarction. The P-Selectin Antagonist Limiting Myonecrosis (PSALM) trial. Am Heart J 152: e1-e8, 2006

55. Versaci F, Gaspardone A, Tomai F, et al: Immunosuppressive therapy for the prevention of restenosis after coronary artery stent implantation (IMPRESS Study). J Am Coll Cardiol 40: 1935-1942, 2002.

56. Almagor M, Keren A and Banai S: Increased C-reactive protein level after coronary stent implantation in patients with stable coronary artery disease. Am Heart J 145: 248-253, 2003.

57. Saadeddin SM and Habbab MA: Percutaneous coronary intervention in the context of systemic inflammation: more injury and worse outcome. Med Sci Monit 9: RA193-RA197, 2003.

58. Goldberg A, Zinder O, Zdorovyak A, et al: Diagnostic coronary angiography induces a systemic inflammatory response in patients with stable angina. Am Heart J 146: 819-823, 2003.

59. Laskey WK and Gellman J: Inflammatory markers increase following exposure to radiographic contrast media. Acta Radiol 44: 498-503, 2003.

60. Arjomand H, Willerson JT, Holmes DR Jr, et al: Outcome of patients with prior percutaneous revascularization undergoing repeat coronary intervention (from the PRESTO Trial). Am J Cardiol 96: 741-746, 2005.

61. Silber S, Albertsson P, Aviles FF, et al: Guidelines for percutaneous coronary interventions: the task force for percutaneous coronary interventions of the European society of cardiology. Eur Heart J 26: 804-847, 2005.

62. Smith SC Jr, Feldman TE, Hirshfeld JW Jr, et al: ACC/ AHA/SCAI 2005 guideline update for percutaneous coronary intervention. J Am Coll Cardiol 47: e1-e121, 2006. 